\title{
Uma nova subespécie de Parides bunichus (Hübner) (Lepidoptera, Papilionidae, Troidini) do interior da Bahia, Brasil ${ }^{1}$
}

\author{
Mirna M. Casagrande ${ }^{2,3} \&$ Olaf H. H. Mielke ${ }^{2,3}$
}

${ }^{1}$ Contribuição $n^{0} 1678$ do Departamento de Zoologia, Universidade Federal do Paraná.

${ }^{2}$ Departamento de Zoologia, Universidade Federal do Paraná, Caixa Postal 19020, 81531-980 Curitiba-PR, Brasil. mibras@ufpr.br, omhesp@ufpr.br ${ }^{3}$ Pesquisador CNPq

\begin{abstract}
A new subspecis of Parides bunichus (Hübner) (Lepidoptera, Papilionidae, Troidini) from the interior of Bahia, Brazil. Parides bunichus almas ssp.nov. is described from Pico das Almas, Rio de Contas, Bahia, Brazil.

KEYWORDS. Neotropical; Papilioninae; Troidina; taxonomy.

RESUMO. Uma nova subespécie de Parides bunichus (Hübner) (Lepidoptera, Papilionidae, Troidini) do interior da Bahia, Brasil. Parides bunichus almas ssp.nov. é descrita com base em material coletado no Pico das Almas, Rio de Contas, Bahia, Brasil.
\end{abstract}

PALAVRAS-CHAVE. Neotropical; Papilioninae; Troidina; taxonomia.

Na porção sudeste da Serra do Sincorá, região central do estado da Bahia localiza-se a Chapada Diamantina que se destaca por abrigar uma grande diversidade tanto florística quanto faunística, cuja riqueza está associada à pluralidade de ecossistemas encontrados na região. O mosaico vegetacional com destaque para a Floresta Atlântica e Caatinga são intercalados por grandes áreas de Cerrado. Estas áreas encontram no clima tropical duas estações bem definidas, enquanto que nas serras, a pluviosidade atuando sobre os afloramentos de rochas, promove a formação de solos que favorecem a instalação de vegetação herbáceo-arbustiva sobre solos arenosos e pedregosos e de composição florística bastante variada. Estas áreas, normalmente acima de 900 metros, constituem os campos rupestres da Chapada.

Entre as maiores elevações desta região, no município de Rio de Contas, encontra-se o Pico das Almas com 1836 m. Neste ambiente, entre altitudes de $1300-1500 \mathrm{~m}$, em horários de sol intenso, entre pedras e árvores de pequeno porte, típicas da região (Fig. 1) coletou-se exemplares machos e fêmeas de um Parides Hübner,[1819], semelhante à Parides bunichus perrhebus (Boisduval, 1836), diferenciando-se deste pelas franjas brancas que contornam ambas as asas. Assemelha-se também à Parides bunichus diodorus (Hopffer, 1865), porém diferencia-se pela ausência das faixas brancas nas asas.

Considerando o isolamento da região do Pico das Almas e as altas taxas de endemismo encontradas em espécies botânicas já citadas por autores com profundo conhecimento da região como Harley \& Giulietti (2004) conclui-se que os exemplares em questão devem pertencer a uma nova subespécie, a qual se denominou Parides bunichus almas.

\section{MATERIALE MÉTODOS}

O material estudado é o citado na série tipo. Dos vinte e seis exemplares estudados, vinte e cinco estão depositados na Coleção Entomológica Pe. J. S. Moure, Departamento de Zoologia, Setor de Ciências Biológicas, Universidade Federal do Paraná e um parátipo na Coleção de Carlos Guilherme C. Mielke, Curitiba, Paraná, Brasil.

Parides bunichus almas Casagrande \& Mielke, ssp. nov. (Figs. 2-5)

Descrição. Macho. Comprimento da asa anterior variando entre 2,6-3,4cm, com as faces dorsal e ventral completamente pretas, sendo esta cor mais intensa na metade basal da asa. Franja estreita de escamas brancas, contornando a margem externa da asa anterior, desde o ápice até o ângulo anal. Asa posterior com as faces dorsal e ventral, igualmente pretas. Franja de escamas brancas, com o dobro da largura, comparada àquela da asa anterior, contornando toda a margem externa; dorsalmente, discretas manchas sub-marginais róseo escuras entre as Medianas, Cubitais e Anal e, ventralmente as manchas mais pronunciadas e presentes desde a $\mathrm{Sc}+\mathrm{R}_{1}$ até a veia Anal.

Palpo labial com escamas róseo escuras. Uma estreita linha de escamas desta cor, com início lateralmente no protórax, se extende abaixo das asas pelo meso e metatórax até a metade basal das coxas nestes segmentos. Estas escamas coloridas também estão presentes na face ventral dos trocânteres meso e metatorácicos e no abdome, sobre a base lateral do primeiro segmento abdominal, esternitos 3 e 4 e pleuras e esternitos do $9^{0}$ segmento. Demais estruturas revestidas de escamas pretas. 

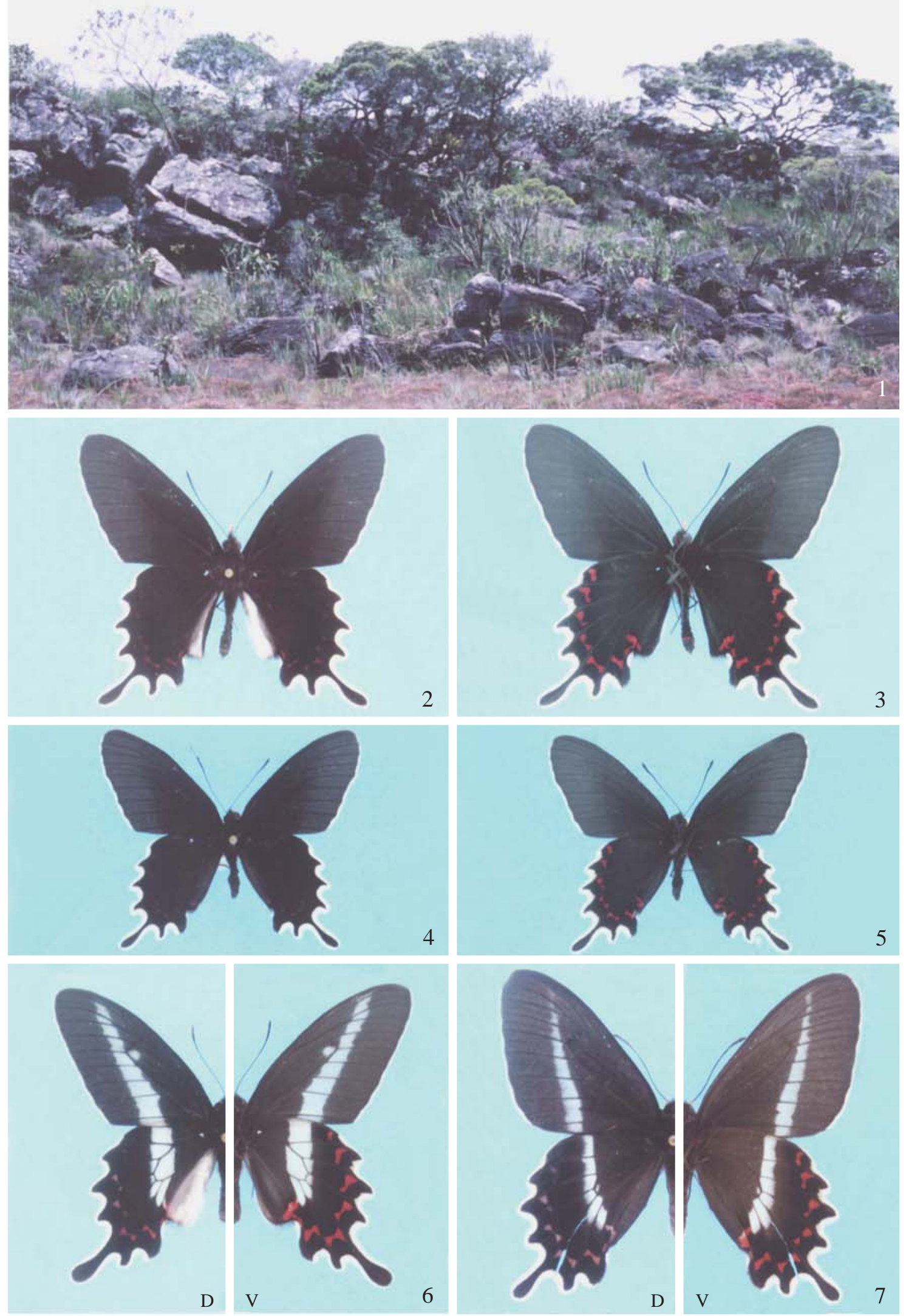

Figs. 1-7. 1, Aspecto geral do ambiente onde foram coletados os exemplares de Parides bunichus almas; 2-5. Parides bunichus almas ssp. nov. 2-3, Holótipo, dorsal e ventral. 4-5, Alótipo, dorsal e ventral. 6-7, Parides bunichus diodorus. 6, macho vistas dorsal e ventral. 7, fêmea vistas dorsal e ventral. 

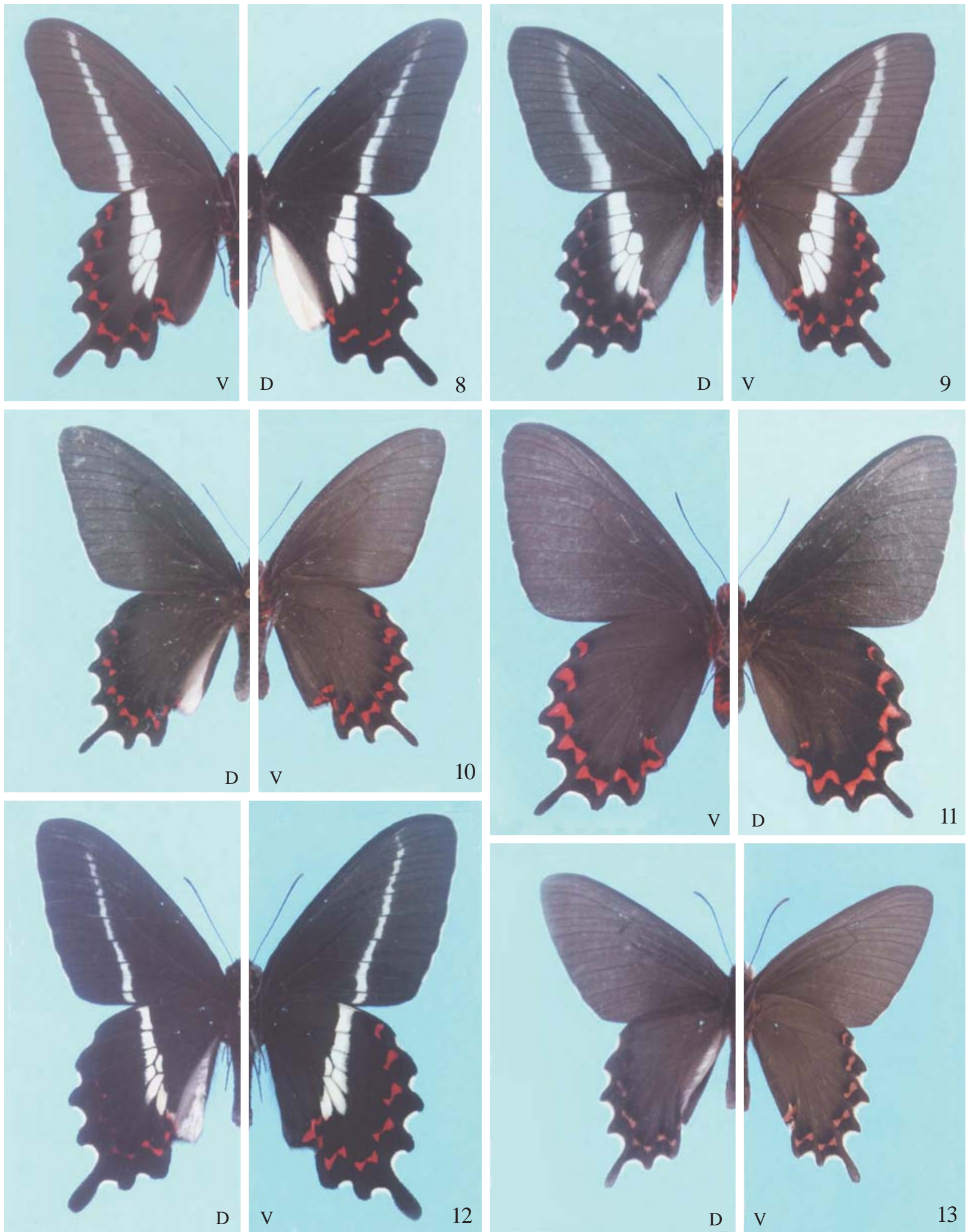

Figs. 8-13. 8-9, Parides bunichus bunichus. 8, macho vistas ventral e dorsal. 9, fêmea vistas dorsal e ventral. 10-11, Parides bunichus perrhebus. 10, macho vistas dorsal e ventral. 11, fêmea vistas ventral e dorsal. 12, Parides bunichus chamissonia. Macho - vistas dorsal e ventral. 13, Parides bunichus damocrates. Macho - vistas dorsal e ventral. 
Comprimento da asa anterior variando entre $2,6-3,5 \mathrm{~cm}$. Mesmo padrão de distribuição de manchas róseo escuras, porém de tonalidade menos intensa. Nos segmentos abdominais, as escamas coloridas contornam ventralmente as porções distal do sétimo e basal do oitavo segmentos, formando um anel ao redor do óstio da bolsa copuladora.

Material tipo: Holótipo macho com as seguintes etiquetas / Holotypus/ 1-II-2005 Pico das Almas, Rio de Contas, Bahia, 1400 - 1600m. Mielke \& Casagrande leg./ DZ 8.774/ Parides bunichus almas Casagrande \& Mielke det., 2007.

Alótipo fêmea com as seguintes etiquetas/ Allotypus/ 1II-2005 Pico das Almas, Rio de Contas, Bahia, 1400 - 1600m. Mielke \& Casagrande leg. / DZ 8.775/ Parides bunichus almas Casagrande \& Mielke det., 2007. Embora pequeno, este exemplar é o que apresenta melhores condições. As outras duas fêmeas são maiores, porém estão muito danificadas.

Parátipos: 8 machos 28-I-2005; 6 machos 31-I-2005; 4 machos e 1 fêmea 1-II-2005; 1 macho 2-II-2005; 1 fêmea 4-7 - XII -2005; 1 macho 25-I-2007, com a mesma procedência do holótipo e alótipo. Um macho 6-XII-2005 Brumadinho, Rio de Contas, Bahia, 1300m Mielke \& Casagrande leg., com os seguintes números respectivamente: DZ 8.769, 8.770, 8.771, 8.776, 8.777, $8.778,8.779,9.696,8.785,8.786,8.787,8.782,8.783,8.784,8.790$, $8.791,8.792,8.793,8.794,8.795,8.798,8.947,8.799$ e um exemplar de 31-I-2005, mesma procedência do holótipo, depositado na coleção de C.G.C.Mielke.

Posição sistemática e discussão.

Segundo Lamas (2005), Parides bunichus (Hübner,[1821]) possui cinco subespécies. De acordo com Hayward (1967), Tyler et al.(1994), Emery et al.(2006) e material na Coleção Pe. J. S. Moure a espécie ocorre desde o interior do Piauí ao Paraguai, norte da Argentina e Uruguai. Parides bunichus bunichus (Hübner, [1821]) (Figs. 8 - 9) com distribuição do interior (oeste) de Minas Gerais até Santa Catarina; Parides bunichus diodorus (Hopffer, 1865) (Figs. 6 -7) em áreas de Cerrado do Piauí, Goiás, Distrito Federal e Minas Gerais; Parides bunichus perrhebus (Westwood, 1872) (Figs. 10 - 11) no oeste de São Paulo e Paraná até Rio Grande do Sul; Parides bunichus chamissonia (Eschscholtz, 1821) (Fig.12) somente no litoral sul de Santa Catarina e Parides bunichus damocrates (Guenée, 1872) (Fig.13) no norte da Argentina.

À primeira vista, os exemplares são muito semelhantes à Parides bunichus perrhebus (Fig. 10 - 11) do sul do Brasil, no entanto, possuem franjas de escamas brancas na margem externa de ambas as asa, que são ausentes naquela. Como a subespécie ocorre em áreas de Cerrado, outra semelhança seria com Parides bunichus diodorus (Figs. 6 - 7) do Cerrado de Minas Gerais e Distrito Federal, mas difere por não possuir as faixas de escamas brancas presentes de forma obliqua em ambas as asas.

Etimologia. O nome da subespécie é alusivo ao local onde a série tipo foi coletada.

\section{REFERÊNCIAS}

Emery, E. O.; K. S. Brown Jr \& C. E. G. Pinheiro. 2006. As borboletas (Lepidoptera, Papilionoidea) do Distrito Federal, Brasil. Revista Brasileira de Entomologia 50: 85-92.

Harley, R. M. \& A. M. Giulietti. 2004. Wild flowers of the Chapada Diamantina. Flores nativas da Chapada Diamantina. Illustrated botanical walks in the montains of $\mathrm{NE}$ Brazil. Trilhas ilustradas nas montanhas do Nordeste do Brasil. RiMa Editora, São Carlos, SP. 319p.

Hayward, K. J. 1967. Insecta, Lepidoptera (Rhopalocera). Familiae Papilionidarum et Satyridarum. In: Descoles, H. R (Ed.), Genera et species animalium argentinorum. Buenos Aires, Guillermo Kraft. 4:[16] + $447+[4]$ pp., 25 pls.

Lamas, G. 2004. Papilionoidae, pp. 87-98. In: G. Lamas (Ed.). Checklist: Part 4A, Hesperioidea-Papilionoidea, 439 pp. In: J. B. Heppner (Ed). Atlas of Neotropical Lepidoptera. Gainesville, Association for Tropical Lepidoptera, Scientific Publishers.

Tyler, H.; K. S. Brown Jr \& K. Wilson. 1994. Swallowtail butterflies of the Americas. A study in biological dynamics, ecological, diversity, biosystematica, and conservation. Gainesville, Scientific Publishers. 376 p.

Recebido em 11/01/2007; aceito em 16/04/2007 